\title{
CORRESPONDENCE.
}

\section{THE YIELD ON A REDEEMABLE BOND WHEN INCOME-TAX IS TAKEN INTO ACCOUNT.}

To the Editors of the Journal of the Institute of Actuaries.

SIrs,-If your readers are not weary of the subject of the effect of income-tax on the yield on a redeemable security, they may possibly find the following formulæ of practical use. The expressions may be approximately derived from formula (6) given by Messrs. 
Lidstone and Todhunter (J.I.A., vol, xlix, p. 369), or more simply from first principles, but they are admittedly in the main empirical, and I am not able to give any theoretical reason why these particular approximations seem to suit present conditions any better than many others.

The true gross yield allowing for tax may be taken as

$$
\begin{aligned}
& \mathrm{J}-\frac{t}{1-t} \cdot \frac{\mathrm{K}-\frac{1}{2} \mathrm{~K}^{2}}{n}, \text { where } \mathrm{K} \text { is negative, } \\
& \mathrm{J}-\frac{t}{1-t} \cdot \frac{\mathrm{K}-\frac{6}{5} \mathrm{~K}^{2}}{n}, \text { where } \mathrm{K} \text { is positive, }
\end{aligned}
$$

$J$ being the gross yield without allowance for tax, $1+K$ the present price, $n$ the outstanding term, and $t$ the rate of tax per unit.

The advantage claimed for these formulæ is simplicity of application. The rate of dividend is not involved, and it is therefore possible to construct a short table of $\frac{t}{1-t}\left(\mathrm{~K}-\frac{1}{2} \mathrm{~K}^{2}\right)$ and $\frac{t}{1-t}\left(\mathrm{~K}-\frac{6}{5} \mathrm{~K}^{2}\right)$ for all prices of securities, for any value of $t$ desired, and divide by $n$ in any particular case required.

As regards accuracy, single examples prove little and are not worth setting out. I have, however, tested the formulæ in about 100 cases for terms from 2 to 40 years, rates of dividend from 3 to 7 per-cent, rates of net yield from $3 \frac{1}{2}$ to 6 per-cent, and rates of tax from 4 s. to $8 s$. in the $£$, and find that for terms of 20 years and under the errors are under $3 d$. per-cent in 77 per cent of the cases, between $3 d$. and $6 d$. per-cent in 15 per-cent, and between $6 d$. and $1 s .6 d$. per-cent in the remainder, which are nearly all cases at the highest rate of tax. For terms over 20 years the errors range up to as much as 3 s. per-cent for the longest term and highest rate of tax, 71 per-cent being under $1 s$. per-cent.

I have compared the errors given by Messrs. Lidstone's and Todhunter's formula in about 30 of the above cases, and find that the latter is somewhat more accurate for terms under 10 years and less accurate for terms over 10 years.

This degree of accuracy seems amply sufficient in dealing with so uncertain a factor as the future rate of income-tax.

$$
\text { Yours faithfully, }
$$

15, St. James's Square, S.W. 1.

O. F. DIVER.

1 March 1920. 